\title{
Lightning Currents Flowing in the Soil and Entering a Test Power Distribution Line Via Its Grounding
}

\author{
Jens Schoene, Member, IEEE, Martin A. Uman, Fellow, IEEE, Vladimir A. Rakov, Fellow, IEEE, \\ Jason Jerauld, Member, IEEE, Keith J. Rambo, D. M. Jordan, G. H. Schnetzer, Mario Paolone, Member, IEEE, \\ Carlo Alberto Nucci, Fellow, IEEE, Emanuel Petrache, Member, IEEE, and Farhad Rachidi, Senior Member, IEEE
}

\begin{abstract}
Current from nearby rocket-triggered lightning that flowed through the soil and into an unenergized test power distribution line was studied based on experimental data acquired in 2003 at the International Center for Lightning Research and Testing in Florida. The 15-pole, three-phase line was 812 m long, was equipped with four arrester stations, at poles $2,6,10$, and 14, and was terminated in its characteristic impedance at poles 1 and 15. The neutral conductor of the line was grounded at each arrester station and at both line terminations. Measurements suggest that a significant fraction of the lightning current injected into the earth a distance of $11 \mathrm{~m}$ from pole 15 entered the line through the grounding system of pole 15 . The peak value of the microsecond-scale return stroke current entering the line through the pole 15 line ground was $7 \%$ of the peak value of the return stroke current injected into the earth. The peak value of the millisecond-scale triggered lightning initial stage current and the millisecond-scale return-stroke and initial-stage charge transfer to the line through the pole 15 line ground was between $12 \%$ and $19 \%$ of the lightning peak current/charge transfer, indicating that the percentage values for the injected peak currents are dependent on the current waveshape: for microsecond-scale return stroke currents, possibly due to electromagnetic coupling effects, a smaller fraction of the current peak enters the line compared to millisecond-scale initial stage currents. In the latter case, any influence of electromagnetic coupling to the line on ground currents is expected to be negligible.
\end{abstract}

Index Terms-Current measurements, electromagnetic coupling, grounding electrodes, grounds, lightning protection, power distribution lines, rocket-triggered lightning.

\section{INTRODUCTION}

$\mathbf{U}$ NDERSTANDING the response of power lines to lightning is imperative in the development of models used in studies of the lightning protection of power lines. Traditionally, these

Manuscript received May 09, 2008; revised August 21, 2008. Current version published June 24, 2009. This work was supported in part by Florida Power and Light Company and in part by the National Science Foundation. Paper no. TPWRD-00340-2008.

J. Schoene is with EnerNex Corporation, Knoxville, TN 37922 USA.

M. A. Uman, V. A. Rakov, K. J. Rambo, D. M. Jordan, and G. H. Schnetzer are with the Department of Electrical and Computer Engineering, University of Florida, Gainesville, FL 32611 USA.

J. Jerauld is with the Raytheon, Tucson, AZ 85706 USA.

M. Paolone and C. A. Nucci are with the University of Bologna, Bologna, Italy.

E. Petrache is with the Kinectrics Inc., Toronto, ON M8Z 6C4, Canada

F. Rachidi is with the Swiss Federal Institute of Technology, Lausanne, Switzerland.

Color versions of one or more of the figures in this paper are available online at http://ieeexplore.ieee.org.

Digital Object Identifier 10.1109/TPWRD.2009.2014031 models simulate either: 1) nearby strike effects resulting from interaction of the power lines with the electromagnetic fields from lightning striking ground in the vicinity and inducing currents and voltages in the line [1]-[5] or 2) direct strike effects, which occur when lightning currents are directly injected into one of the line conductors or other above-ground elements of the line [1], [6]-[11]. In this latter case electromagnetic coupling effects are thought to be relatively small and are usually neglected. However, during a strike to earth close to a power line both nearby (electromagnetic coupling) and direct strike effects can be important. Specifically, if lightning strikes the earth close to a line ground, current is both induced in the line by the coupling of the lightning's electromagnetic fields to the line (a nearby strike effect) and directly injected into the line through its grounds (a direct strike effect). Models that simulate nearby strike effects [2], [3] generally ignore the possibility that some of the lightning current injected into the earth can find its way to the power line. The phenomenon of lightning currents traversing soil and entering line or other installation grounds has been reported by Rakov and Uman [12] and is further investigated here. This phenomenon has implications for understanding the ability of lightning currents traversing soil to cause coal mine explosions [13].

The experiments discussed in this paper were performed at the International Center for Lightning Research and Testing (ICLRT) which is an outdoor facility occupying about $1 \mathrm{~km}^{2}$ at the Camp Blanding Army National Guard Base in north-central Florida, approximately midway between Gainesville, home of the University of Florida, and Jacksonville. At the ICLRT, lightning is triggered (artificially initiated) from natural overhead thunderclouds for a variety of purposes using the rocket-and-wire technique [12], [14], [15]. Triggered lightning is typically composed of an initial stage involving an Initial Continuous Current (ICC) of the order of $100 \mathrm{~A}$ with a duration of hundreds of milliseconds followed by one or more dart leader-return stroke sequences which are very similar to the strokes following the first stroke in natural lightning. An overview of the ICLRT is given in Fig. 1 including a depiction of the two test power distribution lines-a vertically-configured distribution line and a horizontally-configured distribution line on which experiments with direct lightning [9], [10], [16]-[18] and nearby lightning [2], [18] have been performed from 1999 through 2004. Selected results from the 2003 nearby-lightning-strike experiment conducted on the vertically-configured line are presented here. Also shown in Fig. 1 is the mobile rocket launcher used for triggering lightning, whose current was injected into earth a distance of $11 \mathrm{~m}$ from pole 15 . 


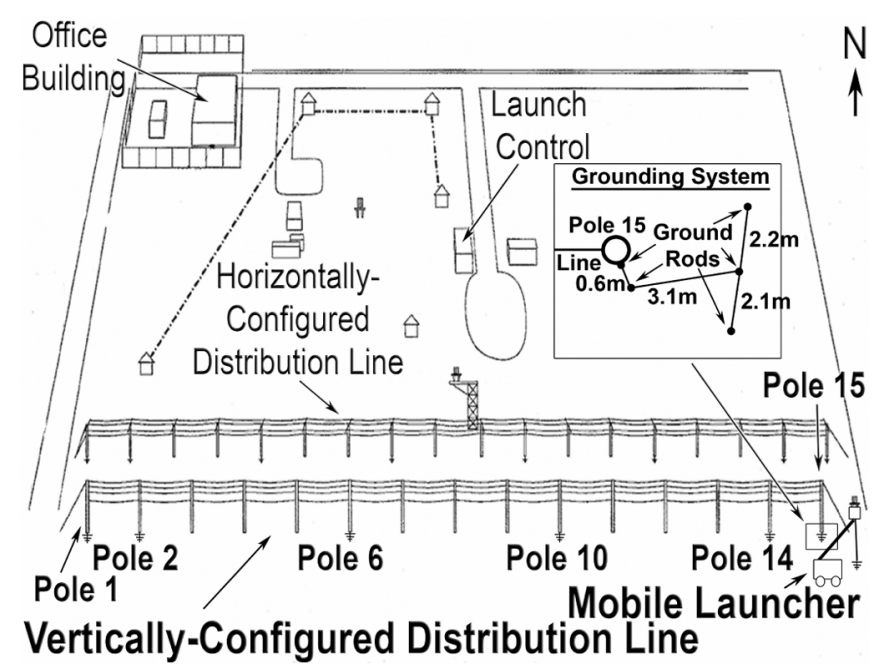

Fig. 1. ICLRT overview, 2003. The poles of the vertically-configured line at which the neutral conductor was grounded are labeled. The pole 15 grounding system (five interconnected vertical rods) including the ground rod locations (solid circles) and the lengths of the wires connecting the ground rods are illustrated in the inset.

\section{EXPERIMENT}

The vertically-configured (vertical) line had four vertically arranged conductors - three phase conductors and one neutral conductor below the phase conductors. It had a length of about $812 \mathrm{~m}$ with 15 wooden poles (average span length: $58 \mathrm{~m}$ ) and arrester stations at poles $2,6,10$, and 14 where $18-\mathrm{kV}$ gapless MOV arresters were installed on all three phases (see the description of the 2003 experiment in [9] and [10] for more details on the arrester specifications). At each end of the line a 500 $\Omega$ terminator was installed between each phase and the neutral conductor in order to minimize reflections there. The line neutral was grounded at each arrester station and at both line terminations using multiple ground rods (see Fig. 1 for the pole 15 grounding system). The number of ground rods used for the pole- 1 , pole- 2 , pole- 6 , pole- 10 , pole-14, and pole-15 groundings were $4,1,5,2,5$, and 5 , respectively. The low-frequency, low-current grounding resistances measured using a clamp-on meter were $24,20,18,18,28$, and $24 \Omega$ for poles $1,2,6,10,14$, and 15 , respectively. Note that the resistance values vary with changing moisture content of the soil.

Lightning was triggered from a mobile launcher in order to simulate induced effects on the line due to nearby lightning. The mobile launcher is a utility service vehicle with a rocket launcher installed in its "bucket" (Fig. 2). Lightning terminated on the launcher and its current was injected into the earth through a "grounding wire" (Fig. 2), which connected the rocket launcher to multiple interconnected vertical ground rods in the vicinity of the launcher. The distance from the launcher grounding system to that of pole 15 was about $11 \mathrm{~m}$. The height of the rocket launcher was approximately $8 \mathrm{~m}$ above ground. The primary reason for elevating the launcher was to create a grounded structure that was higher than the power line so that a downward triggered-lightning leader would attach to the launcher and not to the line. A very close lightning strike near a "real world" power distribution line can occur if a tall structure

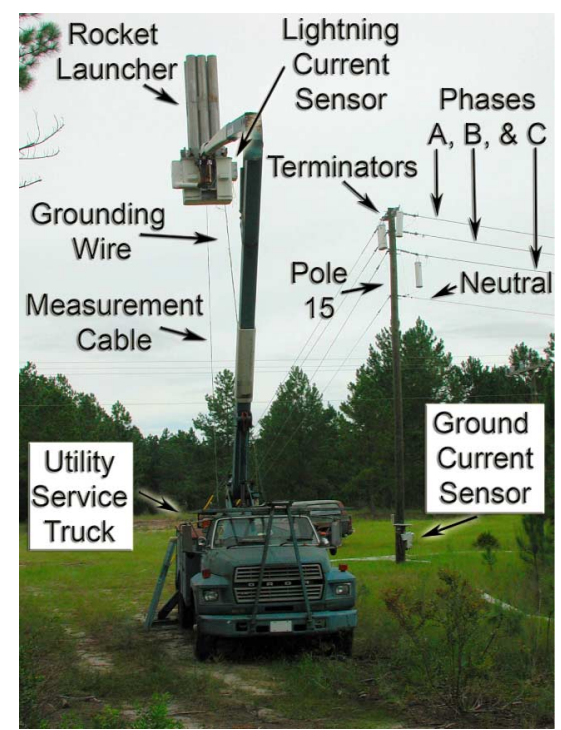

Fig. 2. Mobile launcher placed $11 \mathrm{~m}$ from one end of the vertically-configured test distribution line. Pole 15 of the test distribution line can be seen on the right. The lightning current sensor is located at the rocket launcher and the ground current sensor is located at the bottom of pole 15 .

(e.g., a tree) is present very close to the line and lightning strikes this structure rather than the line.

During a given rocket-triggered lightning event, we measured simultaneously currents at 25 different locations on the line and at the launcher. A $2.5 \mathrm{~m} \Omega$ noninductive current viewing resistor (CVR) with a frequency response of 0 to $48 \mathrm{MHz}$ was installed at the rocket launcher to measure the lightning channel-base current. Six CVRs with V/A ratings of $1 \mathrm{~m} \Omega$ and $1.25 \mathrm{~m} \Omega$ and frequency responses of 0 to $9 \mathrm{MHz}$ and 0 to $12 \mathrm{MHz}$, respectively, measured the currents flowing through the six ground leads that connected the line's neutral conductor with the ground rods. Eighteen current transformers (CTs) measured currents flowing in the phase and neutral conductors, and through the arresters and terminators. Each of the measured current signals was transmitted to the Launch Control trailer (Fig. 1) via a Nicolet Isobe 3000 link (upper frequency response: $15 \mathrm{MHz}$ ) composed of a receiver-transmitter pair and a connecting fiber optic cable. The launch control trailer housed two 12-bit Yokogawa DL716 oscilloscopes, six 8-bit LeCroy Waverunner LT344L oscilloscopes, and one 8-bit LeCroy 9354 oscilloscope, which provided a total of 60 digital channels to record the current signals. The Yokogawa oscilloscopes sampled continuously for $2 \mathrm{~s}$ at 2 $\mathrm{MHz}$ in 2003. The LeCroy oscilloscopes sampled at $20 \mathrm{MHz}$ and recorded in ten 5-ms or five 10-ms segments. The Yokogawa and LeCroy data were lowpass filtered at 500 and $5 \mathrm{MHz}$, respectively, to avoid aliasing.

\section{General Data Presentation}

Fig. 3 shows lightning and line ground currents during two events: 1) the initial stage (IS) of flash FPL0350 and 2) the return stroke FPL0350-1. The IS current and return stroke current measured at the lightning channel base and injected into the earth a distance of $11 \mathrm{~m}$ from pole 15 are displayed on the left side of Fig. 3. The ground currents measured at poles $15,14,10,6$, 2, and 1 are displayed at the bottom. Negative polarity indicates 


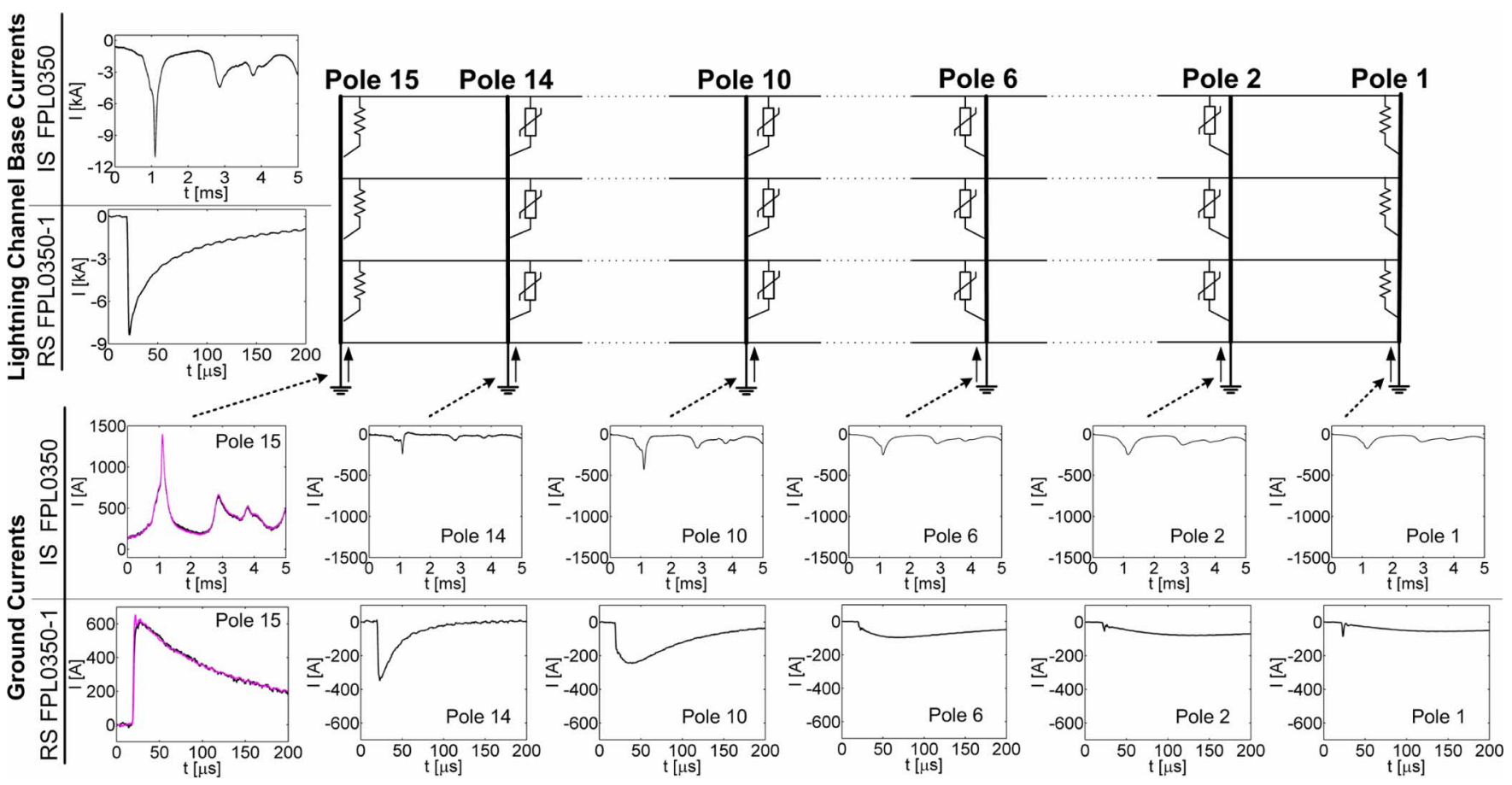

Fig. 3. Sketch of all test distribution line poles with line grounds and the measured lightning and line ground currents. Lightning currents during the initial stage (IS) of flash FPL0350 displayed on a $5 \mathrm{~ms}$ time scale and the first return stroke (RS) in flash FPL0350 displayed on a $200 \mu$ s time scale are shown on the top-left. Ground currents during both events are displayed at the bottom. Additionally, the pole 15 ground current is overlaid with the total current flowing through the other line grounds (the polarity of the total current was inverted for better comparison with the pole 15 current). The pole 15 ground current (into the system) and the sum of currents flowing through the other line grounds (out of the system) are essentially equal.

negative charge flowing into the earth and positive polarity indicates negative charge flowing out of the earth. The positive polarity of the pole 15 ground current is indicative of lightning current (negative charge) entering the line from the earth and the negative polarity of the ground currents measured at the other poles indicates current (negative charge) leaving the line. Additionally, the ground current measured at pole 15 and the sum of the currents measured at the other line grounds (the polarity of the current sum is inverted to facilitate comparison with the pole 15 current) are essentially indistinguishable for the two events of Fig. 3 during which no arrester current flowed, that is, the current entering the line at pole 15 is equal to the total current leaving the line at the other grounded poles. Note that only 5 $\mathrm{ms}$ of the IS current is shown for illustrative purposes. The actual duration of the IS was hundreds of milliseconds. Note also that the IS current was unusually large (11 kA peak value); typically IS currents have magnitudes in the range of hundreds of amperes.

During the first $10 \mu \mathrm{s}$ or so of return stroke FPL0350-1, the ground currents leaving the line are largest at the poles closest to the current injection point at pole 15, illustrating that the higher-frequency components of the return stroke current injected to the grounding system at pole 15 primarily flow to the earth through the line grounds that are closer to pole 15 , which is a result of the blocking effect of the inductive impedance of the line, as discussed in [10] for lightning currents directly injected into one of the phase conductors. Also, similar to the current division during direct current injection discussed in [10], the lower frequency components appear to preferably flow through the pole grounds with low grounding resistance; for instance, Fig. 3 shows that for stroke FPL0350-1, the pole-14 ground current at $200 \mu \mathrm{s}$ (pole 14 has the largest grounding resistance) is essentially zero, while current still flows through the other pole grounds.

Figs. 4 and 5 compare lightning current waveshapes during an initial stage and a return stroke, respectively, with currents entering the line through the pole 15 line ground. The currents during the initial stage are shown on a millisecond time scale, and the return-stroke currents are shown on $1 \mathrm{~ms}$ [Fig. 5(a)] and $50 \mu$ s time scales [Fig. 5(b)]. Note that the ground currents and lightning currents in the same figure have different vertical scales to allow a comparison of their waveshapes-the vertical scales of the ground currents are displayed on the left side and the vertical scales of the lightning currents are displayed on the right side of the figures. Note also that Fig. 4 shows only a 10-ms time interval of the IS for illustrative purposes-as noted earlier, the total duration of the IS is hundreds of milliseconds.

\section{ANALYSis of Total LightNing CURRENTS AND CURRENTS INJECTED INTO DISTRIBUTION LINE GROUNDS}

Table I gives the peak values for the total currents and corresponding charges of three return strokes and three Initial-Stage (IS) currents and compares them with the peak values of the currents and charges entering the line through the pole 15 line ground. The charge transfer was obtained by numerically integrating the measured return stroke currents and the IS currents 

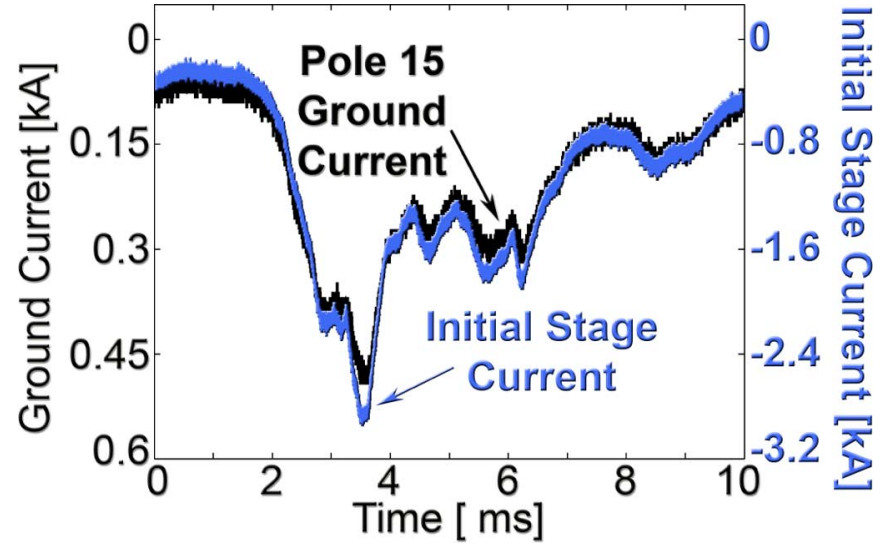

Fig. 4. Initial stage of flash FPL0348: lightning current (negative charge) injected into the earth a distance of $11 \mathrm{~m}$ from pole 15 (blue, right vertical scale) and current (negative charge) injected into the line through the pole 15 ground (black, left vertical scale).

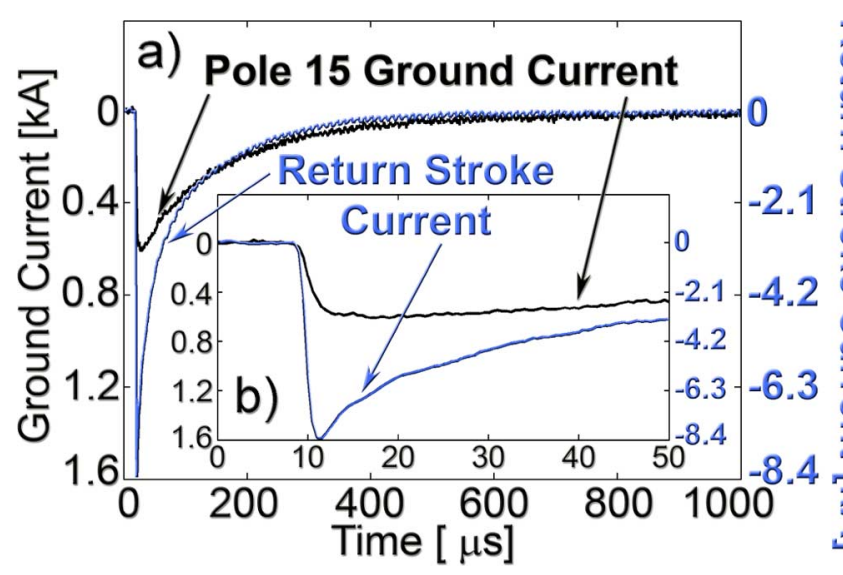

Fig. 5. Return stroke FPL0350-1: lightning current (negative charge) injected into earth $11 \mathrm{~m}$ from pole 15 (blue, right vertical scale) and current (negative charge) injected into the line through the pole 15 line ground (black, left vertical scale).

over a $1 \mathrm{~ms}$ time interval and a 10-ms time interval, respectively ${ }^{1}$.

Table I shows that the percentage of the return stroke current peaks entering the line through the pole 15 line ground is significantly smaller than the percentage of the IS current peaks entering the line (return stroke events: 7\%, initial stage events: between $12 \%$ and 17\%). This trend is illustrated in Fig. 6 where the peaks of the pole 15 ground currents (y-values) are plotted against the lightning current peaks (x-values). The return stroke current peaks and IS current peaks are each linearly correlated with the corresponding pole 15 ground current peaks (for both return stroke and initial stage events: $R^{2}=1.00$, where $R^{2}$ is the coefficient of determination), but the linear regression equations are different for the return stroke and initial stage events (return stroke events:

\footnotetext{
${ }^{1} \mathrm{~A}$ longer time interval was chosen to determine the charge transfer during the IS due to the longer duration of the IS current compared to the return stroke current. The length of the integration time interval to determine the IS charge does not affect the percentage of lightning charge entering the line (last column in Table I) since the charge injected into the pole 15 line ground and the lightning charge have very similar waveshapes (see Fig. 4).
}

TABLE I

COMPARISON OF PEAK VALUES AND CHARge TRANSFers OF TOTAL LightNING CURRENTS AND CURRENTS ENTERING THE LINE THROUGH THE Pole 15 Ground. The Charge Transfers Were ObTaINED by NuMERICALLY INTEGRATING THE MEASURED CURRENTS OVER 1 MS (RETURN STROKE CURRENT) AND 10 MS (INITIAL-STAGE CURRENT) TIME INTERVALS

\begin{tabular}{|c|c|c|c|c|c|c|}
\hline \multirow{2}{*}{ Event ID } & \multicolumn{2}{|c|}{$\begin{array}{c}\text { Peak Current } \\
\text { Value [kA] }\end{array}$} & \multirow{2}{*}{$\begin{array}{c}\text { Percentage Of } \\
\text { Lightning Current } \\
\text { Peak Entering Line } \\
{[\%]}\end{array}$} & \multicolumn{2}{|c|}{\begin{tabular}{|c|} 
Charge transfer \\
within $1 \mathrm{~ms} / 10 \mathrm{~ms}[\mathrm{C}]$
\end{tabular}} & \multirow{2}{*}{$\begin{array}{c}\text { Percentage of } \\
\text { Lightning Charge } \\
\text { Entering Line } \\
{[\%]}\end{array}$} \\
\hline & Lightning & $\begin{array}{l}\text { Pole } 15 \\
\text { Ground }\end{array}$ & & Lightning & $\begin{array}{l}\text { Pole 15 } \\
\text { Ground }\end{array}$ & \\
\hline FPL0347-1 & 20.1 & 1.4 & 7 & 1.79 & 0.30 & 17 \\
\hline FPL0347-2 & 6.1 & 0.5 & 7 & 0.41 & 0.08 & 19 \\
\hline FPL0350-1 & 8.4 & 0.6 & 7 & 0.58 & 0.11 & 19 \\
\hline FPL0347-IS & 5.2 & 0.7 & 14 & 16.82 & 2.73 & 16 \\
\hline FPL0348-IS & 2.9 & 0.5 & 17 & 10.84 & 2.02 & 19 \\
\hline FPL0350-IS & 11.1 & 1.4 & 12 & 18.25 & 3.18 & 17 \\
\hline
\end{tabular}

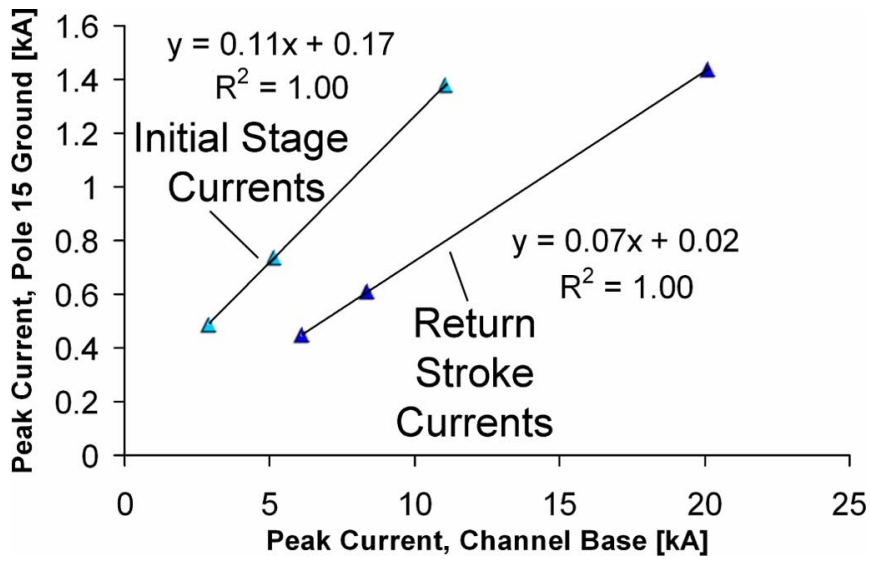

Fig. 6. Peak current injected into the line through the ground of pole 15 as a function of the peak current injected into the earth a distance of $11 \mathrm{~m}$ from pole 15 . The linear regression equations and $\mathrm{R}^{2}$ values are given.

$\mathrm{y}=0.07 \mathrm{x}+0.02$, initial stage events: $\mathrm{y}=0.11 \mathrm{x}+0.17)^{2}$. The two different regression equations indicate that the percentage of the lightning current entering the line through the ground of pole 15 depends on the current waveshape, so that a smaller fraction of the current peak enters the line for fast (microsecond-scale) return stroke currents than for the slow (millisecond-scale) IS currents.

A similar comparison of the charge transfers within $1 \mathrm{~ms}$ (return stroke events) and $10 \mathrm{~ms}$ (initial stage events) shows that the fraction of the lightning charge entering the line through the pole 15 line ground is very similar for the return stroke and initial stage (between $16 \%$ and 19\%, see Table I). Consequently, only one regression equation is needed to describe the relationship between the lightning charge transfer to earth and the charge transferred into the line through the pole 15 line ground $\left(y=0.17 x+0.02, R^{2}=0.99\right.$, see Fig. 7). In other words, the percentages of the lightning charge entering the line through the pole 15 line ground on a 1-ms time scale (return stroke events) and on a 10-ms time scale (initial stage events) are very similar.

The findings in the previous two paragraphs show that during millisecond-scale lightning currents and charge transfers (that is, the IS current and the $1 \mathrm{~ms}$ charge transfer during the return strokes and the 10-ms charge transfer during the initial stage) the

${ }^{2}$ Note that each of the two coefficients of determination in Fig. 6 was determined for only three data points. The apparent perfect correlation suggested by the two unity $\mathrm{R}^{2}$ values would likely deviate from unity if more data points were available. 
lightning current and the current injected into the line ground closest to the lightning have the same waveshape (see the initial stage and the pole 15 ground currents in Fig. 4). On the other hand, during microsecond-scale return strokes, the lightning current and the current injected into the closest line ground have different waveshapes for the first $100 \mu$ s, or so (see the total return stroke and the pole 15 ground current waveshapes in Fig. 5). The following paragraph further investigates this feature by comparing the risetimes and half-peak widths of the total return stroke and pole 15 ground currents.

Table II shows the 10\%-90\% risetime and half-peak width of the total lightning return stroke current injected into the earth and compares them with the $10 \%-90 \%$ risetimes and half-peak widths of the currents entering the line through the ground of pole 15 . The table includes the ratio between $10 \%-90 \%$ risetimes/half-peak widths of the total lightning return stroke currents and the currents entering the line through the pole 15 line ground. The 10\%-90\% risetimes of the pole 15 ground currents are 2.1 to 3.0 times larger than the risetimes of the total lightning return stroke currents. The half-peak widths of the pole 15 ground currents are 2.5 to 5 times larger than the half-peak widths of the total lightning return stroke currents.

The slower front and larger half-peak widths of the pole 15 ground currents compared to total lightning return stroke currents suggest an analogy with a low-pass filter that has the lightning current as input and the ground current as output. It is not clear which mechanism "filters" the lightning current, but the different (degraded) initial potion of the waveshape of the current through the closest line ground is likely related to effects of: 1) the current induced in the line by the lightning electromagnetic pulse (LEMP); 2) the properties of soil that the lightning current traverses; and/or 3) the impedance of the system that the lightning current "sees" when it enters the line. Apparently only return stroke current pulses (which are less than $100 \mu \mathrm{s}$ or so in duration) are significantly degraded (see Fig. 5). In the "low-pass filter" analogy, this translates to a cutoff frequency of about $10 \mathrm{kHz}$. In other words, waveforms with no appreciable frequency content above $10 \mathrm{kHz}$ traverse the soil at Camp Blanding and enter the line system essentially unaffected, which is indeed the case for the IS current and charge.

An experiment similar to the present one was conducted at Camp Blanding by Fernandez et al. [19] who studied a 730-mlong test distribution line with two vertically stacked conductors supported by 15 poles. The bottom conductor simulated the neutral and was grounded at poles 1,9 , and 15 . The line was terminated at both ends in its characteristic impedance of 500 $\Omega$. No arresters or other equipment were installed on the line. It was found that for a $17-\mathrm{kA}$ rocket-triggered lightning stroke $20 \mathrm{~m}$ from the line about 890 A (5\% of the lightning return stroke current peak) entered the neutral conductor through the line ground at pole 9 located $40 \mathrm{~m}$ from the strike point. In our experiment the fraction of the total lightning return stroke current peak entering the line through the pole 15 line ground, $7 \%$, is similar to the 5\% found in the experiment of Fernandez et al. This similarity is somewhat unexpected, since the distance between the lightning current injection point and the closest line ground in the experiment of Fernandez et al. was almost four times larger than in the present experiment $(40 \mathrm{~m}$ versus $11 \mathrm{~m}$

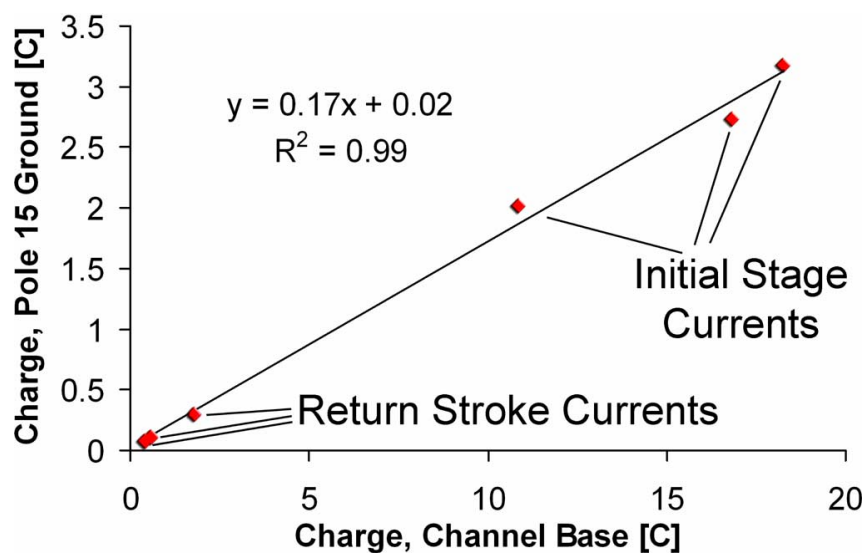

Fig. 7. Charge injected into the line through the ground of pole 15 as a function of lightning charge injected into the earth a distance of $11 \mathrm{~m}$ from pole 15 . The linear regression equation and $\mathrm{R}^{2}$ value are given. The integration time used to obtain the charge transfers from the return stroke currents and initial-stage (IS) currents was 1 and $10 \mathrm{~ms}$, respectively.

TABLE II

COMPARISON OF 10-90\% RISETIMES AND HALF-PEAK WIDTHS OF TOTAL LIGHTNING CURRENTS AND CURRENTS ENTERING THE LINE THROUGH THE GROUND OF POLE 15

\begin{tabular}{|c|c|c|c|c|c|c|}
\hline \multirow{2}{*}{ Event ID } & \multicolumn{2}{|c|}{$\begin{array}{c}10-90 \% \text { Risetime } \\
\text { Of Current [us] }\end{array}$} & \multirow{2}{*}{$\begin{array}{c}\text { Ratio Of Pole } 15 \\
\text { Ground Current } \\
\text { And Lightning } \\
\text { Current Risetimes }\end{array}$} & \multicolumn{2}{|c|}{$\begin{array}{l}\text { Half-Peak Width } \\
\text { Of Current [ } \mu \mathrm{s}]\end{array}$} & \multirow{2}{*}{$\begin{array}{l}\text { Ratio Of Pole } 15 \\
\text { Ground Current And } \\
\text { Lightning Current } \\
\text { Half-Peak Widths }\end{array}$} \\
\hline & Lightning & $\begin{array}{l}\text { Pole 15 } \\
\text { Ground }\end{array}$ & & Lightning & $\begin{array}{l}\text { Pole 15 } \\
\text { Ground }\end{array}$ & \\
\hline FPL0347-1 & 0.9 & 2.7 & 3.0 & 54 & 135 & 2.5 \\
\hline FPL0347-2 & 1.0 & 2.6 & 2.5 & 17 & 85 & 5.0 \\
\hline FPL0350-1 & 1.4 & 2.9 & 2.1 & 24 & 98 & 4.0 \\
\hline
\end{tabular}

in our experiment). The soil through which the lightning currents in both experiments flowed was probably similar since both experiments were conducted at the same experimental site, although some soil variation is expected since the experiment locations were separated by hundreds of meters and rainfall could significantly change the soil conductivity on different days. The current injected into the pole 9 line ground in the experiment of Fernandez et al. exhibited damped oscillation during the first $10 \mu \mathrm{s}$ after the initial peak, which had a $3.2 \mu$ s period and a maximum peak-to-peak value of about $400 \mathrm{~A}$ (the initial peak value of the pole 9 ground current was $890 \mathrm{~A}$, as noted above). Fernandez et al. attributed the oscillation to wave reflections at the pole 1,9 , and 15 line grounds. In our experiment oscillations were not seen in any of the pole 15 ground currents even though the same mechanism that allegedly caused the oscillations in Fernandez et al. should also have caused oscillation in our current (the upper bandwidth of our ground current measurement was $5 \mathrm{MHz}$, which was sufficient to measure such microsecond-scale oscillations). The reason for the discrepancy is presently unknown.

In two other and different experiments conducted at Camp Blanding and summarized by Rakov and Uman [12], 18\% of the current of a $20 \mathrm{kA}$ rocket-triggered lightning stroke entered the grounding system of a test house $19 \mathrm{~m}$ from the strike point, and $10 \%$ of the current of a rocket-triggered lightning stroke entered the ground of a transformer at a distance of $60 \mathrm{~m}$ from the strike point [20]. For both events larger percentages of the lightning return stroke peak currents (18\% and 10\%) entered the 
nearby grounds than the $7 \%$ in our experiment, even though the distances of the lightning current injection points to the grounds were larger (19 $\mathrm{m}$ and $60 \mathrm{~m}$ versus $11 \mathrm{~m})$.

\section{OBSERVEd EFFECT OF INJECTED CURRENTS ON ARRESTER CURRENTS}

It was shown in the previous sections that for lightning strikes to earth at a distance of $11 \mathrm{~m}$ from pole 15 a significant fraction of the total lightning return stroke current was injected into the neutral conductor of the vertically-configured line through the ground of pole 15 . This section investigates how arrester operation is affected by this current.

We focus on the arrester currents during the 20-kA stroke FPL0347-1. The line arresters conducted current only during this stroke; apparently neither the other two return strokes nor the three initial stage currents (see Table I) induced a large enough voltage between the phase and neutral conductors to cause an arrester to operate. Fig. 8 compares the measured currents in the phase A arresters at poles 14, 10, 6, and 2 during stroke FPL0347-1. The currents were filtered with a $2-\mathrm{MHz}$, fifth-order Butterworth digital low-pass filter. The figure shows that the arrester at pole 14, the arrester closest to the strike point $11 \mathrm{~m}$ from pole 15 , does not conduct negative current ${ }^{3}$. On the other hand, the other three arresters (that is, the arresters at poles 10,6 , and 2) do conduct negative currents. Note that the time of operation of these arresters depends on their proximity to the lightning; the pole 10 arrester operates first, and the pole 6 and pole 2 arresters operate $0.8 \mu \mathrm{s}$ and $1.5 \mu \mathrm{s}$, respectively, after the pole 10 arrester operates. Currently available models for calculating currents and voltages on power lines due to nearby lightning strikes (e.g., [1]-[5]) do not explain the experimental result that the closest arrester at pole 14 does not conduct negative current. In fact, preliminary modeling results show not only negative current in all arresters but also negative current in the closest arrester at pole 14 to be over four times larger than the current in the pole 2 arrester (the arrester furthest away from the lightning).

The non-operation (or operation not as predicted by electromagnetic coupling models) of the pole 14 arrester is apparently due to the fact that the lightning current directly injected into the neutral conductor at pole 15 reduces the lightning-induced voltage (due to electromagnetic coupling) between the phase conductors and neutral conductor thereby preventing the pole 14 arrester from opening. The lightning current injected into the neutral also reduces the lightning-induced phase-to-neutral voltage at the other arrester poles, but to a lesser degree since a large fraction of the current injected into the pole 15 line ground leaves the line through the pole 14 and 10 line grounds (see Fig. 3). This observation has the following implication: The

\footnotetext{
${ }^{3}$ The pole 14 arrester does conduct about $50 \mathrm{~A}$ of positive current. The time of the positive current pulse corresponds to the time of arrival of a LEMP induced current wave that was reflected at an impedance discontinuity at pole 10 (that is, the phase A arrester at pole 10). The reflected wave from an operating arrester (basically a short circuit) has opposite polarity relative to the original (incident) electromagnetically-induced wave. Apparently, the positive current pulse in the pole 14 arrester is due to the reflected current wave in combination with the effect of negative charge in the neutral due to direct current injection, which results in a large enough voltage to cause pole 14 arrester operation with current flow in the "opposite" direction.
}

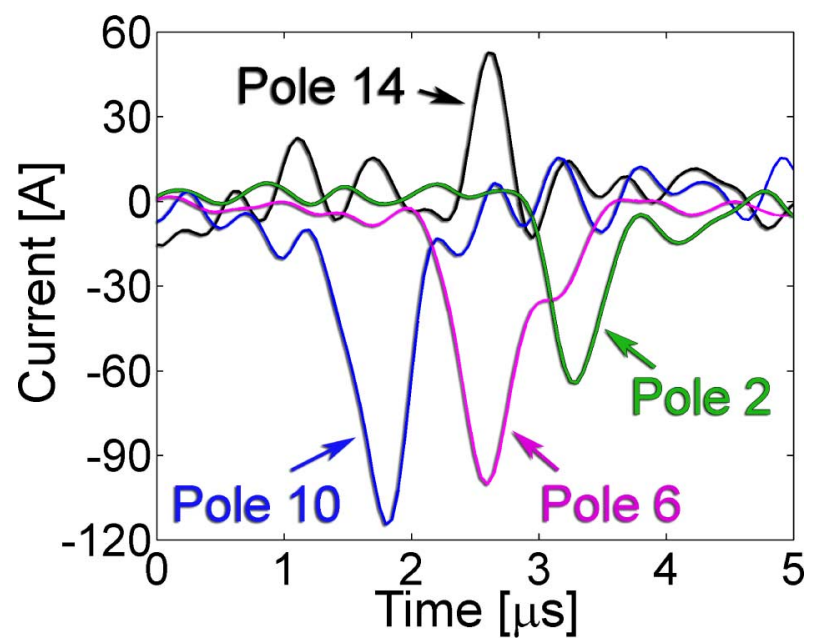

Fig. 8. Measured phase A arrester currents during stroke FPL0347-1 at pole 14 , pole 10 , pole 6 , and pole 2 .

fraction of the lightning current injected into the neutral conductor through the line ground closest to the lightning strike to earth reduces the lightning-induced voltage between phase and neutral conductors most strongly near the current injection location (pole 15 in our experiment) and less strongly down the line thereby reducing the potential for flashovers due to induced overvoltages that may otherwise occur on lines without arresters or on lines with large arrester spacing. Consequently, induced overvoltage models which do not take this effect into account overestimate lightning-induced phase-to-neutral voltages (and thereby overestimate the number of phase-to-neutral flashovers due to nearby lightning) on line segments that have a neutral ground close to the lightning strike point.

\section{SUMMARY}

Currents measured on a test power distribution line during a lightning strike to earth $11 \mathrm{~m}$ from the line ground at pole 15 were investigated. Our interpretation of the measured currents at the poles 15, 14, 10, 6, and 2 line grounds is that some ground current is due to direct strike effects, that is, the ground potential rise due to lightning current flowing through the ground drives negative charge into the line's neutral conductor through the pole 15 ground, this charge leaving the neutral conductor at the other line grounds. However, the measured ground currents also have some contribution from indirect strike effects, that is, currents due to electromagnetic coupling between the lightning channel and the line conductors. Modeling results to be presented in a future paper will shed some light on what the relative contributions of direct and indirect effects are.

The negative charge in the neutral conductor reduces the lightning-induced voltage between phase conductors and neutral conductor thereby helping prevent flashovers due to induced voltages that may otherwise occur on lines without arresters or on lines with large arrester spacing. This effect is strongest near the injection point and decreases with distance from the injection point. Models for calculating overvoltages on distribution lines due to nearby lightning should account for this effect. 
We characterized the nearby-lightning current flowing into the line at the pole 15 grounding, which is important for the development of nearby lightning strike models that include the direct current injection effects described in the previous paragraph. The results can be summarized as follows.

a) The peak value of the lightning current/magnitude of charge injected into the earth a distance of $11 \mathrm{~m}$ from pole 15 and the peak value of the current/magnitude of charge injected into the line through the pole 15 line ground are strongly linearly correlated.

b) The percentage of the total lightning current peak entering the pole 15 line ground is considerably lower for microsecond-scale return stroke currents $(7 \%$ for three events) than it is for millisecond-scale initial stage currents $(12,14$, and $17 \%)$. The millisecond-scale return stroke and initial stage charge transfers behave similar to the initial stage current, that is, between 16 and $19 \%$ of the lightning charge enters the pole 15 line ground.

c) The waveshapes of the millisecond-scale initial stage currents and the associated pole 15 ground currents are very similar, probably because in this case the electromagnetic coupling effects are negligible.

d) The waveshapes of the microsecond-scale return stroke currents and the associated pole 15 ground currents are different for the first $100 \mu \mathrm{s}$ or so. The $10-90 \%$ risetimes of the return stroke currents entering the line through the pole 15 line ground are 2 to 3 times larger than the risetimes of the return stroke currents injected into the earth $11 \mathrm{~m}$ away. The half-peak widths of the return stroke currents entering the line through the pole 15 line ground are 2.5 to 5 times larger than the half-peak widths of the return stroke currents injected into earth $11 \mathrm{~m}$ from pole 15 .

Based on the waveshape comparisons of the lightning current and the pole 15 ground current in the last two items, we suggest an analogy with a low-pass filter that "filters" the lightning current above $10 \mathrm{kHz}$. The "filtered" lightning current enters the line at the pole 15 ground. The "filtered" waveshape of the current through the pole 15 line ground is likely related to effects of: 1) the current induced in the line by the LEMP; 2) the soil that the lightning current traverses; and/or 3) the impedance of the system that the lightning current encounters when it enters the pole 15 ground.

\section{REFERENCES}

[1] P. Chowdhuri, "Lightning-induced voltages on multiconductor overhead lines," IEEE Trans. Power Del., vol. 5, no. 2, pp. 658-667, Apr. 1990.

[2] M. Paolone, J. Schoene, M. A. Uman, V. A. Rakov, D. Jordan, K. J. Rambo, J. Jerauld, C. A. Nucci, A. Borghetti, F. Rachidi, and E. Petrache, "Testing of the LIOV-EMTP96 code for computing lightning-induced currents on real distribution lines: Triggered-lightning experiments," in Proc. Int. Conf. Lightning Protection, 2004.

[3] F. Rachidi, C. A. Nucci, M. Ianoz, and C. Mazzetti, "Response of multiconductor power lines to nearby lightning return stroke electromagnetic fields," IEEE Trans. Power Del., vol. 12, no. 3, pp. 1404-1411, Jul. 1997.

[4] S. Rusck, "Induced lightning overvoltages on power transmission lines with special reference to the overvoltage protection of low voltage networks," Trans. Roy. Inst. Technol., no. 120, 1958.
[5] S. Yokoyama, "Calculation of lightning-induced voltages on overhead multiconductor systems," IEEE Trans. Power App. Syst., vol. PAS-103, no. 1, pp. 100-108, Jan. 1984.

[6] C. T. Mata, V. A. Rakov, K. J. Rambo, P. Diaz, R. Rey, and M. A. Uman, "Measurement of the division of lightning return stroke current among the multiple arresters and grounds of a power distribution line," IEEE Trans. Power Del., vol. 18, no. 4, pp. 1203-1208, Oct. 2003.

[7] Y. Matsumoto, O. Sakuma, K. Shinjo, M. Saiki, T. Wakai, T. Sakai, H. Nagasaka, H. Motoyama, and M. Ishii, "Measurement of lightning surges on test transmission line equipped with arresters struck by natural and triggered lightning," IEEE Trans. Power Del., vol. 11, no. 2, pp. 996-1002, Apr. 1996.

[8] H. Motoyama, Y. Matsumoto, and N. Itamoto, "Observation and analysis of multiphase back flashover on the Okushishiku test transmission line caused by winter lightning," IEEE Trans. Power Del., vol. 13, no. 4, pp. 1391-1398, Oct. 1998

[9] J. Schoene, M. A. Uman, V. A. Rakov, A. G. Mata, C. T. Mata, K. J. Rambo, J. Jerauld, D. M. Jordan, and G. H. Schnetzer, "Direct lightning strikes to test power distribution lines-Part 1: Experiment and overall results," IEEE Trans. Power Del., vol. 22, no. 4, pp. 2236-2244, Oct. 2007a.

[10] J. Schoene, M. A. Uman, V. A. Rakov, A. G. Mata, C. T. Mata, K. J. Rambo, J. Jerauld, D. M. Jordan, and G. H. Schnetzer, "Direct lightning strikes to test power distribution lines-Part 2: Measured and modeled current division among multiple arresters and grounds," IEEE Trans. Power Del., vol. 22, no. 4, pp. 2245-2253, Oct. 2007.

[11] P. P. Barker, R. T. Mancao, D. J. Kvaltine, and D. E. Parrish, "Characteristics of lightning surges measured at metal oxide distribution arresters," IEEE Trans. Power Del., vol. 8, no. 1, pp. 301-310, Jan. 1993.

[12] V. A. Rakov and M. A. Uman, Lightning: Physics and Effects. Cambridge, U.K.: Cambridge Univ. Press, 2003.

[13] T. Novak and T. J. Fisher, "Lightning propagation through the earth and its potential for methane ignitions in abandoned areas of underground coal mines," IEEE Trans. Ind. Appl., vol. 37, no. 6, pp. 1555-1562, Nov./Dec. 2001.

[14] V. A. Rakov, "Lightning discharges triggered using rocket-and-wire techniques," Recent Res. Devel. Geophys., pp. 141-171, 1999.

[15] M. A. Uman, V. A. Rakov, K. J. Rambo, T. W. Vaught, M. I. Fernandez, D. J. Cordier, R. M. Chandler, R. Bernstein, and C. Golden, "Triggeredlightning experiments at Camp Blanding, Florida (1993-1995),” Trans. IEE Jap., vol. 117-B, pp. 446-452, 1997.

[16] A. G. Mata, "Interaction of Lightning With Power Distribution Lines: 2001 and 2002 Experiments at the International Center for Lightning Research and Testing (ICLRT)," Master's thesis, Univ. of Florida, Gainesville, 2003.

[17] C. T. Mata, "Interaction of lightning with power distribution lines," $\mathrm{Ph}$.D. dissertation of philosophy, Univ. Florida, Gainesville, 2000

[18] J. Schoene, "Direct and nearby lightning strike interactions with test power distribution lines," Ph.D. dissertation of philosophy, Univ. Florida, Gainesville, FL, 2007.

[19] M. I. Fernandez, K. J. Rambo, M. V. Stapleton, V. A. Rakov, and M. A. Uman, "Review of triggered lightning experiments performed on a power distribution system at Camp Blanding, Florida, during 1996 and 1997," in Proc. 24th Int. Conf. Lightning Protection, Birmingham, U.K., 1998, pp. 29-35.

[20] M. I. Fernandez, "Responses of an Unenergized Test Power Distribution System to Direct and Nearby Lightning Strikes," Master's thesis, Univ. of Florida, Gainesville, 1997.

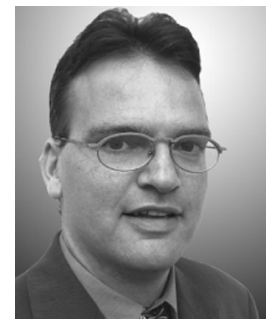

Jens Schoene (M'07) received the Dipl.-Ing. degree from the Department of Electrical Engineering, University of Paderborn, Soest, Germany, in 1999 and the M.S. and Ph.D. degrees in electrical engineering from the University of Florida, Gainesville, in 2002 and 2007, respectively.

From 1999 to 2006, he was a Research Assistant at the International Center for Lightning Research and Testing (ICLRT), Camp Blanding, Starke, $\mathrm{FL}$, where he was engaged in research on many aspects of lightning, including the response of power distribution line to direct and nearby lightning strikes. In 2007, he joined EnerNex, Knoxville, TN, as a Power Systems Engineer. He is the author of six peer-reviewed scientific papers, coauthor of ten peer-reviewed scientific papers published in peer-reviewed journals, and author or coauthor of 14 conference proceedings. 


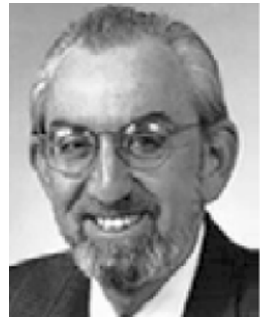

Martin A. Uman (F'88) received the Ph.D. degree from Princeton University, Princeton, NJ, in 1961.

$\mathrm{He}$ is a Distinguished Professor at the Department of Electrical and Computer Engineering, University of Florida, Gainesville. He was an Associate Professor of Electrical Engineering at the University of Arizona, Tucson, from 1961 to 1964 . He joined the University of Florida faculty in 1971 after working for seven years as a Fellow Physicist at Westinghouse Research Labs, Pittsburgh, PA. He cofounded and served as President of Lightning Location and Protection Inc. (LLP) from 1975 to 1985 . He has written five books on the subject of lightning, as well as a book on plasma physics, and has published over 180 papers in reviewed journals. He holds six patents, five in the area of lightning detection and location.

Dr. Uman is the recipient of the 1996 IEEE Heinrich Hertz Medal for outstanding contributions to the understanding of lightning electromagnetics and its application to lightning detection and protection" and the 2001 AGU John Adam Fleming Medal for original research and technical leadership in geomagnetism, atmospheric electricity, space science, aeronomy, and related sciences: for outstanding contribution to the description and understanding of electricity and magnetism of the Earth and its atmosphere." HE is a Fellow of the AGU and the AMS.

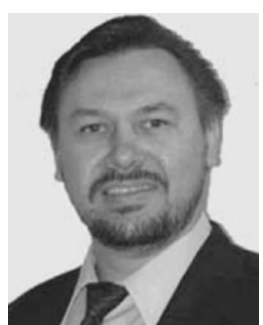

Vladimir A. Rakov (SM'96-F'03) received the M.S and $\mathrm{Ph} . \mathrm{D}$. degrees in electrical engieering from the Tomsk Polytechnic University (Tomsk Polytechnic), Tomsk, Russia, in 1977 and 1983, respectively.

From 1977 to 1979, he was an Assistant Professor of Electrical Engineering at Tomsk Polytechnic. In 1978, he became involved in lightning research at the High Voltage Research Institute (a division of Tomsk Polytechnic), where from 1984 to 1994 , he held the position of Director of the Lightning Research Laboratory. He is currently a Professor at the Department of Electrical and Computer Engineering, University of Florida, Gainesville, and Co-Director of the International Center for Lightning Research and Testing (ICLRT). He is the author or co-author of one book, ten book chapters, over 30 patents, and over 450 papers and technical reports on various aspects of lightning, with over 160 papers being published in reviewed journals.

Dr. Rakov is the Chairman of the Technical Committee on Lightning of the Biennial International Zurich Symposium on Electromagnetic Compatibility, Convener of CIGRE Working Group C4-407 "Lightning Parameters for Engineering Applications," and former Chairman of the AGU Committee on Atmospheric and Space Electricity (CASE). He is a Fellow of AMS and IET and a member of AGU.

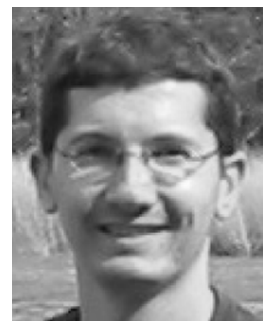

Jason Jerauld (M'98) received the B.S., M.S., and $\mathrm{Ph} . \mathrm{D}$. degrees in electrical engineering from the University of Florida, Gainesville, in 2001, 2003, and 2007, respectively.

From 2001 to 2005 , he participated in natural and rocket-triggered lightning experiments at the International Center for Lightning Research and Testing (ICLRT), Camp Blanding, FL. During 2005, he served as Assistant Director for Operations and Experiments at the ICLRT, supervising the summer research program. In 2008, he joined Raytheon Missile Systems, Tucson, AZ, as a Senior Electrical Engineer, focusing on antenna design and electrical analysis of radomes. He is the author or coauthor of over 70 papers and technical reports on various aspects of lightning, with over 20 papers published in reviewed journals.

Dr. Jerauld is a recipient of the 2004-2007 NASA Florida Space Grant Consortium Fellowship.

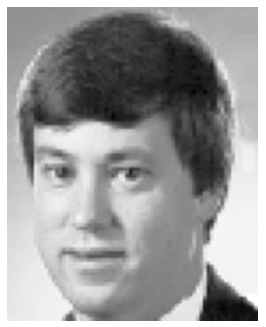

Keith J. Rambo received the B.S.E.E. degree from the University of Florida (UF), Gainesville, in 1978.

As an undergraduate, he worked in the UF Lightning Research Laboratory. From 1979 to 1983, he was a Senior Process Development Engineer at Intel Corporation, Santa Clara, CA. During 1983-1986, he was a Product Line Manager for Xicor, responsible for all aspects of wafer fabrication. In 1986, he joined the UF Department of Electrical and Computer Engineering, where since 1989 he has been Director of Technical Support Services. Since 1994, he has been heavily involved in triggered lightning experiments at Camp Blanding, FL. He has ten technical publications.

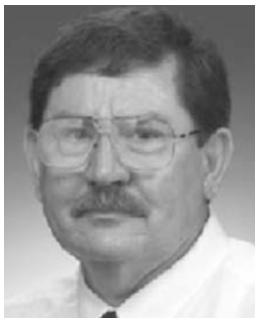

Douglas Jordan received the $\mathrm{Ph} . \mathrm{D}$. degree from the University of Florida, Gainesville, FL, in 1990.

$\mathrm{He}$ was a Founding Faculty Member of both the University of North Florida Electrical and Computer Engineering Department and the University of West Florida Electrical and Computer Engineering Department. In 2000, he returned to the University of Florida, Gainesville, as a Lecturer and Undergraduate Coordinator. He is now a Senior Lecturer and continues research on the optical and electromagnetic properties of lightning.

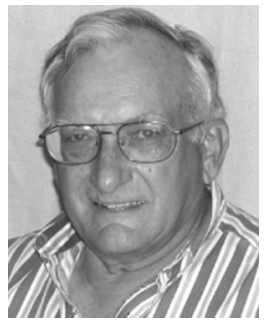

George H. Schnetzer received the B.S.E.E. degree from the University of Missouri in 1962 and the M.S.E.E. degree from the University of New Mexico, Albuquerque, in 1965.

He was with Sandia National Laboratories from 1962 to 1973 and from 1974 to his retirement. During his tenure at Sandia, he was primarily involved in the areas of antenna development, radar system development, and electromagnetic testing. From 1973 to 1974, he was with the Boeing Co., Seattle, WA, as an Antenna Design and Development Engineer. He holds a patent for an omnidirectional horizontally-polarized antenna and has published several reports on antenna design, propagation experiments, and electromagnetic tests.

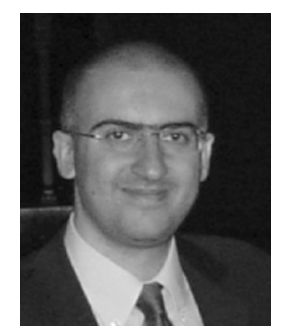

Mario Paolone (M'07) was born in Campobasso, Italy, in 1973. He received the electrical engineering degree (Hons.) in 1998 and the Ph.D. degree in 2002, both from the University of Bologna, Bologna, Italy.

$\mathrm{He}$ is currently working within the Power Systems Group of the University of Bologna, Bologna, Italy. His research interests are power system transients, with particular reference to LEMP-interaction with electrical networks, power systems dynamics, power system protections and distributed generation. He is the author or coauthor of over 90 scientific papers published in reviewed journals and presented at international conferences.

Dr. Paolone is a member of the IEEE Working Group on Lightning Performance of Distribution Lines and of the joint CIGRE-CIRED Working Group "Protection of MV and LV networks against Lightning". 


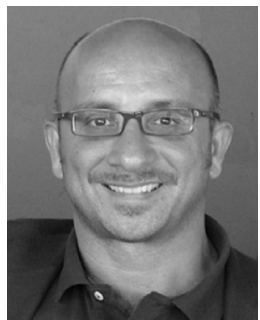

Carlo Alberto Nucci (M'91-SM'02-F'07) was born in Bologna, Italy, in 1956. He received the M.S. (Hons.) and Ph.D. degrees in electrical engineering from the University of Bologna, in 1982 and 1986, respectively.

At the same university, he was a Researcher at the Power Electrical Engineering Institute since 1983, became an Associate Professor in 1992, and in 2000 became a Full Professor and Chair of Power Systems. He is author or co-author of more than 200 scientific papers published in reviewed journals or presented at international conferences. His research interests concern power systems transients and dynamics, with particular reference to lightning impact on power line, system restoration after black-outs, and distributed generation.

Dr. Nucci is a member of the IEEE Working Group on Lightning Performance of Distribution Lines and Chairman of the Study Committee C4 "System Technical performance" of CIGRE. Since January 2005, he has been Regional Editor for Africa and Europe of the Electric Power System Research journal (Elsevier). $\mathrm{He}$ is also a Fellow of the IET.

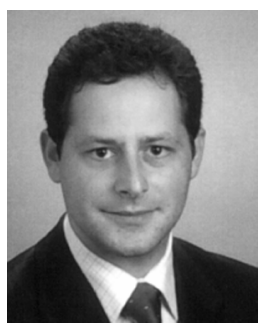

Emanuel Petrache (S'02-M'04) was born in Constanta, Romania, in 1975. He received the M.S. degree in electrical engineering from the University Politehnica of Bucharest, Bucharest, Romania, in 1998 and the Ph.D. degree from the Swiss Federal Institute of Technology, Lausanne, Switzerland, in 2004.

From 2004 to 2006, he was a Postdoctoral Fellow at the University of Toronto, Toronto, ON, Canada, in the Lightning Studies Group. In 2006, he joined Kinectrics (formerly the Ontario Hydro Research Division). His research interests include numerical computation of electromagnetic fields, lightning, and electromagnetic field interactions with transmission lines.

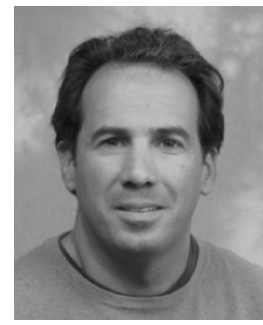

Farhad Rachidi (M'93-SM'02) received the M.S. degree in electrical engineering and the Ph.D. degree from the Swiss Federal Institute of Technology, Lausanne, Switzerland, in 1986 and 1991, respectively.

He worked at the Power Systems Laboratory of the Swiss Federal Institute of Technology until 1996. In 1997, he joined the Lightning Research Laboratory, University of Toronto, Toronto, ON, Canada, and from April 1998 until September 1999, he was with Montena EMC (Switzerland). He is currently a Professor and Head of the EMC Group at the Swiss Federal Institute of Technology. He is the author or coauthor of over 200 scientific papers published in reviewed journals and presented at international conferences.

Dr. Rachidi is the Convener of the joint CIGRE-CIRED Working Group "Protection of MV and LV networks against Lightning", and a member of various IEEE, CIGRE, and CIRED working groups dealing with lightning. He is Vice Chair of the European COST Action P18 "The Physics of Lightning Flash and its Effects" and an Associate Editor of the IEEE TRANSACTIONS ON ELECTROMAGNETIC COMPATIBILITY and of the Journal of Lightning Research He was the recipient of the 2005 IEEE EMC Technical Achievement Award, the 2005 CIGRE Technical Committee Award, and the 2006 Blondel Medal. 